

\section{Incarceration Rates}

In 2016 there were approximately 2.3 million individuals incarcerated in U.S. federal, state and local institutions (Wagner \& Rabuy, 2016). Andrews and Bonta (2010) noted that persons incarcerated in criminal justice institutions were disproportionately minorities; 1 in 15 African American men and 1 in 36 Hispanic/Latino reside in prison. Nearly $40 \%$ of all persons in jail or prison are African American (Brennan Center for Justice, 2015). Incarceration in the U.S. has increased 500\% over the past four decades, and the U.S. is now the world leader in incarceration, outpacing Russia by $36 \%$ per capita (Sentencing Project, 2015). Changes in sentencing laws have played a major role in these increases, particularly laws applicable to drug offenses. In a paper reviewing criminal justice policy and practice, Andrews and Bonta (2010) noted that the U.S. adopted a "get tough" on crime approach in the 1970's that led to increased incarceration of person who Were arrested and longer minimum time periods for their incarceration. Because the criminal justice approach focused more on punishment than rehabilitation, obstacles were created to employment, housing, services, and education that would allow previously incarcerated persons to succeed in the community. The result was more incidences of repeated offenses and increased recidivism. Between 1980 and 2014 the number of persons incarcerated for drug offenses in federal, state, and local criminal justice institutions increased from 40,900 to 488,400 (Sentencing Project, 2015).

\section{Prison Overcrowding and Cost}

Despite the large increase of persons incarcerated for drug offenses, there is little evidence public safely has improved (Andrews \& Bonta, 2010). For example, in a review of prisoner reentry (Bushway, 2006) cited data indicating 68\% of all individuals released from state prisons are rearrested within three years. Nearly half (43\%) Were arrested in the first six months after release. Chandler, Fletcher and Volkow (2009) attributed high rates of reincarceration to the fact that $80 \%$ to $85 \%$ of prisoners who could benefit from drug treatment do not receive it.

Instead of decreasing crime and recidivism, incarceration has exacerbated a variety of problems (Andrews \& Bonta, 2010). For example, criminal justice costs have soared. Between 1985 and 2013, state expenditures on corrections increased from $\$ 6.7$ billion to $\$ 51.9$ billion. Incarceration has also led to seriously overcrowded prisons and jails leading to legal action in a number of states. For example, in 2006, California had the largest state prison system in the U.S. with over 173,000 persons incarcerated, but the maximum capacity was approximately (Warren, 2006). The extent of overcrowding resulted in a lawsuit that went to the U.S. Supreme Court in 2011. The court ruled that state prisons in California must release nearly 40,000 incarcerated persons because the extent of overcrowding in state prisons made it impossible to provide adequate medical and mental health care (Lofstrom \& Martin, 2015). One strategy to comply with the order was to transfer 9,000 prisoners to outof-state prison facilities (Eaglin, 2015), which makes it difficult for family members to maintain contact or take part in any type of family services. The state also increased reliance on private facilities within California by sending 2,000 persons to such facilities. These 
strategies have further contributed to exorbitant costs. In 2015, California spent over $\$ 12$ billion on incarceration of offenders (Eaglin, 2015).

\section{Health and Social Consequences}

In addition to exorbitant costs, overcrowding in prisons and jails has resulted in numerous health and social consequences during and after incarceration. Petersilia (2003) and Petteruti and Walsh (2008) noted overcrowded condition in these institutions are associated with increased prisoner violence and exacerbated mental health disorders. In addition, these conditions fuel transmission of infections such as HIV and hepatitis C (Chandler, Fletcher \& Volkow, 2009). Because previously incarcerated persons are under tested and under treated for infectious diseases, they can put others at risk during and after release from incarceration.

Incarceration affects entire families in addition to the individuals sentenced. Incarcerated persons frequently become isolated from intimate partners, their families, and their communities. They often lose their jobs and in some jurisdictions lose their housing (Petteruti \& Walsh, 2008; Petersilia, 2003). Often overlooked in analyses of criminal justice policies are the consequences of incarceration on children. The majority of persons incarcerated in state $(55 \%)$ and federal $(63 \%)$ prisons report having at least one minor child (Waul, Travis, \& Solomon, 2002). The Brennan Center for Justice (2015) reported one in 28 children has a parent in prison. These children often suffer trauma because of forced separation from their parents as well as challenges adapting to the return of their parents after they are released. (Waul, et al., 2002) pointed out that most families with an incarcerated parent had already been dealing with multiple financial and social stresses before the arrest occurred and subsequent incarceration only made them worse.

\section{Efforts to Reduce Incarceration}

There is growing consensus that America's "war on drugs" has failed to curtail drug-related crime and has generated multiple unintended consequences (Andrews \& Bonta, 2010). In addition, the issue of criminal justice reform has gained broad attention among diverse stakeholders, including lawmakers, faith leaders, and civil rights leaders, all of which has contributed to a more receptive political environment for criminal justice reform (Porter, 2017). As a result, efforts at local, state, and federal level are being made to reduce the population of inmates in prisons and jails. In a publication supported by the Sentencing Project (Porter, 2017) described a number of policy changes states are making. She pointed out that 17 states in 2016 adopted reforms targeted at reducing prison populations. Examples of new policies include expanding incarceration alternatives, reducing lengths of incarceration, reclassifying drug possession as a misdemeanor offense, streamlining parole releases for persons sentenced for a first-time nonviolent offense, and eliminating mandatory minimum limits. In 2011, California enacted a state law (AB109), which transitions persons in the state prison system to local jurisdictions, often with reduced incarceration periods (Lofstrom \& Martin, 2015). In 2014, California voters passed proposition 47, a ballot initiative designed to reduce felony drug offenses to misdemeanors and provide funding for mental health and drug treatment. 
The policy changes being enacted within criminal justice systems appear to be having an impact. The Brennan Center for Justice (2016) noted that states are making reductions in their incarcerated populations. Over the past 10 years, 27 states reduced their overall incarceration rates, and between 2006 and 2014 incarceration in state prisons dropped 7\%. Some states with the largest drops in their prison populations also experienced the largest reductions in crime. Eaglin (2015) reported that reductions in the numbers of incarcerated persons are occurring in both state prisons and local jails. For example, Los Angeles County, the largest jail system in the country, has seen its jail population decline by $17 \%$ since implementation of proposition 47 in 2014.

\section{Role of Recovery Residences}

Triaging large numbers of parolees arrested for drug offenses to alternative dispositions in the community raises a number of challenges. Among the most serious is finding stable housing that supports successful re-entry (Harding, Morenoff \& Herbert, 2013). Housing can also be problematic for persons on probation. Petteruti and Walsh (2008) noted that affordable housing is often difficult to find for persons released from local jails because they often lose their jobs when they are incarcerated. In addition to affordability, housing for criminal justice populations needs to support abstinence from drugs and alcohol, access to needed services (e.g., medical, mental health, and job training) and development of a prosocial recovery lifestyle (Polcin, 2006).

In some states, recovery residences for alcohol and drug problems play important roles in providing housing for persons on probation or parole. The National Association for Recovery Residences (National Association of Recovery Residences, 2012) identified four types or levels of residences, which Were summarized by (Polcin, Mericle, Hoewell, Sheridan, \& Christensen, 2014).

- Level I residences are peer-managed houses located in residential neighborhoods. The residents themselves run them using a democratic voting process and there are no paid staff members or on-site services. Oxford Houses are good examples of these residences (Jason, Olson, \& Foli, 2008).

- Level II residences are also typically located in residential neighborhoods. Unlike Level I houses, they are managed by a house manager or senior resident who is either paid or receives a reduction of rent. There are typically no services offered on-site and residents are usually mandated or strongly encouraged to attend 12-step recovery groups. Sober Living Houses in California are good examples of these residences (Polcin, Korcha, Bond, \& Galloway, 2010).

- $\quad$ Level III residences employ paid staff who provide on-site services, such as linkage to resources in the community, recovery Illness planning, recovery support groups, and life skills training. (Mericle, Miles, \& Cacciola, 2015) pointed out that these can be considered hybrid programs that combine social model recovery and additional services delivered by trained staff. Some Level III residences exist as private households in residential neighborhoods while others operate in multifamily, commercial, or other environments. 
- $\quad$ Level IV residences are best understood as residential treatment programs that are more structured than level III and that provide a variety of on-site clinical services. Although some staff may be in recovery, Level IV's employ licensed or credentialed professionals. Therapeutic communities (TC's) (De Leon, 2000; De Leon, 2010) are a good example of level IV facilities. These facilities are typically not zoned as ordinary housing in residential neighborhoods.

Historically, TC's have been the most common type of recovery residence serving parolees and studies have generally supported their efficacy for this population. For example, DeLeon (1988) found that criminal justice referred clients had longer lengths of stay in TC's than voluntary clients and commensurate levels of improvement on drug, alcohol, and other outcomes. Prendergast, Hall, Wexler, Melnick, \& Cao (2004) conducted a randomized trial of 715 prisoners who were assigned either to a TC condition or to a no treatment control group. At 5-year follow-up, the TC group had significantly lower rates of re-incarceration, but not shorter times to first re-incarceration. Martin, Butzin, and Inciardi (1995) studied 457 individuals participating in either an in-prison TC, a TC in the community, both types of TCs, or a no treatment comparison group. Those attending the community-based TC or both types of TC had significantly better outcomes on measures of substance use and re-arrests.

Another type of recovery residence serving criminal justice involved populations is Oxford House (level one). In a national study of Oxford Houses Jason, Davis and Ferrari (2007) found 30\% of the residents living at Oxford Houses Were on probation or parole (Jason, Davis, \& Ferrari, 2007). More recently, two Oxford House studies targeted assessment of outcomes for parolees. One assessed 270 individuals who had been released by the criminal justice system during the past two years (Jason, Olson, \& Harvey, 2015). Most participants (93\%) Were enrolled in residential substance abuse treatment programs. Participants were assigned to one of three conditions: TC, Oxford House, or aftercare as usual. Participants were followed up for 24 months. Longer lengths of stay in the TC and Oxford House conditions were associated with better employment, alcohol and drug outcomes.

Comparison of study conditions showed Oxford Houses had better outcomes than the other two conditions for days worked and income. In addition, a cost-benefit analysis showed more favorable ratios for the Oxford House condition. Other variables, including days of substance use, legal problems, and psychiatric hospitalizations, did not show differences between the study conditions. However, the investigators did report a significant effect for days of continuous alcohol sobriety over the 24-month follow-up period. Sixty-six percent of the Oxford House participants reported continuous abstinence from alcohol. For the TC condition, the abstinence rate from alcohol was $40 \%$ and for the usual aftercare condition, it was $49 \%$. Continuous abstinence rates for drugs did not differ between study conditions.

Another study of Oxford Houses for persons involved in the criminal justice system assessed 200 women with criminal justice involvement who were recruited from substance abuse treatment and criminal justice programs (Jason, Salina, \& Ram, 2015). Participants were assigned to an Oxford House or usual aftercare condition. For the Oxford House condition, length of time in the house (6 months or more) was associated with better alcohol and drug use, employment, and self-efficacy outcomes. However, outcomes for those in the $\mathrm{OH}$ condition were not significantly different from aftercare as usual. 
Less studied than Oxford Houses and TC's are outcomes among parolees and probationers residing in level two and level three residences. However, one study of 245 residents living in level two sober living houses (SLHs) in northern California found $29 \%$ of the sample was referred through the criminal justice system (Polcin, Korcha, Bond, \& Galloway, 2010). Like the overall sample, persons referred from the criminal justice system made significant gains on measures of alcohol and drug use that Were maintained at 18-month follow-up (Polcin, Korcha, Wittman, \& Troutman, 2010). However, criminal justice referred residents were more likely to be arrested at follow-up time points and they had greater difficulty finding and maintaining employment.

Part of the reasons for these findings might be related to the concerning finding that many individuals on probation or parole did not receive the professional services they felt they needed. Polcin, Korcha, Wittman, and Troutman (2010) found that criminal justice previously incarcerated persons received only $35 \%$ of the services they thought they needed to succeed in recovery.

One of the advantages of level three residences (Mericle et al., 2015) is they offer a variety of on-site services to address resident needs and in some cases more actively work to connect residents to services they need in the community. While outcomes for criminal justice involved residents have not been studied in these residences, they may be more appropriate than level two settings for persons who present with more serious needs. However, one of their drawbacks may be that unlike Oxford Houses and SLHs, many of them have a maximum length of stay. Thus, a resident may be required to leave the home before they feel ready or before they have made other living arrangements.

One of the limitations of recovery residences is that they emphasize a goal of abstinence and some individuals arrested for drug offenses may not want to be abstinent. Supportive housing programs that do not require abstinence may be an option for some of these individuals. For example, Housing First (HF) is a supportive housing model that provides free or subsidized housing to persons who are homeless, many of whom have mental health and substance abuse problems (Tsemberis, Gulcur \& Nakae, 2004). The program emphasizes a "low threshold" with personal choice about whether to address substance abuse and mental health problems. Thus, HF provides permanent housing largely without conditions. However, many criminal justice involved persons are required to abstain from substances as a condition of probation or parole. In those cases, HF might not offer sufficient support for abstinence and could put them at risk for relapse and re-incarceration (Polcin, 2016).

\section{Influencing Criminal Justice and Housing Policy}

The political landscape in the U.S. has shifted dramatically since the 2016 election and one of the repercussions has been a return to drug policies based on fear rather than science. Attorney general Jeff sessions has called for increased incarceration for drug offenses and a simplistic "just say no" approach to prevention that was advocated by the Reagan administration in the 1980's (Horwitz, 2017). The counterproductive effects of these policies over the past three decades has been ignored in favor of stoking fears about the recent 
increase in opioid dependence and overdoses. The opioid epidemic in the U.S. is tragic and requires an aggressive response. However, attorney general Sessions has not put forth an aggressive, science-based plan to combat opioid problems among criminal justice involved persons. Instead, it appears the U.S. will once again be filling its prisons with persons arrested for drug offenses. Given the current political landscape, it behooves providers, researchers, consumers, and advocates to increase their efforts to influence policies that will determine the viability of alternatives to incarceration and the potential role of recovery residences. Our work will need to include efforts to engage stakeholders, particularly policymakers, in discussions about the advantages of recovery residences for previously incarcerated persons.

Improving dissemination of research findings will be a critical component of influencing policy. It will not be enough to publish results in professional journals and feel the work of dissemination is complete. In multiple forums that include different stakeholder groups (e.g., policymakers, service providers, professionals, researchers, consumers, and the general public), we will need to articulate the human and financial costs of using incarceration as a response to drug offenses as well as the advantages of offering a variety of services, including recovery housing, in the community. For example, we need better dissemination of the public health consequences of incarceration for inmates, families, and communities. We also need to disseminate studies showing the improvements recovery home residents make, including decreasing substance use, finding employment, decreasing arrests, and improving relationships with family members.

There are a number of existing studies of recovery residences that could be better disseminated among stakeholder groups and more influential in influencing policies. While there is research documenting favorable outcomes for a variety of individuals living in recovery residences (National Association of Recovery Residences, 2012) including criminal justice populations (Jason, et al., 2015; Polcin, 2006), NIMBY ("not in my back yard") views continue to be problematic for many providers (Polcin, et al., 2014). Resistance to recovery residences occurs in spite of data dispelling the notion that recovery homes are associated with decreases in property values or increases in crime (American Planning Association, 2003; Deaner, Jason, Aase, \& Mueller, 2009). Studies of level I and II residences show they are perceived good neighbors (Heslin et al. 2012; Jason et al., 2008; Polcin, Henderson, Trocki, Evans, \& Wittman, 2012). It is noteworthy that these studies show when neighbors are familiar with the recovery homes in their neighborhoods and with the residents who live there, they tend to be supportive. Drug treatment counselors and mental health professionals show similar responses. A study of their views about sober living houses in California showed high levels of support for sober living houses and those who were most familiar with these homes Were most supportive (Polcin et al., 2012).

There is a significant need for a range of new studies. Research is desperately needed to better assess previously incarcerated person needs and match their characteristics with the appropriate residence levels within NARR. In addition, there are questions needing to be addressed about the types of previously incarcerated persons who might do best in a residence designated for previously incarcerated persons versus a generic residence with a mix of different types of residents. Currently, criminal justice professionals are faced with a 
variety of housing options for persons on their caseloads and it is unclear what types of residences should be encouraged for different probationers and parolees. There is also a need for research that examines outcomes within a broader context that includes examination of the social environments within the houses, the neighborhoods where they are located, and services offered with recovery systems of care in the local community. Finally, it is problematic that there are only a few research teams studying level I and II residences (Polcin et al., 2016). For research to maximize its impact, it will require multiple teams confirming the findings of one another and developing new studies and new directions that can move the field forward.

\section{Acknowledgments}

This work was supported by the National Institute on Drug Abuse, grant number DA034973. Rachael Korcha, M.A. and Elizabeth Mahoney, M.A. provided helpful feedback on earlier drafts of the manuscript.

\section{References}

American Planning Association. Policy Guide on Homelessness. Chicago, IL: 2003. Accessed: 2014-04-28. Archived by WebCite ${ }^{\circledR}$ at http://www.Webcitation.org/6PB6eCxHy

Andrews DA, Bonta J. Rehabilitating criminal justice policy and practice. Psychology, Public Policy, and Law. 2010; 16(1):39.

Brennan Center for Justice. Justice Update: Majority of States Cut Both Crime and Incarceration. New York: 2016. [Accessed: 2016-09-23]. https://Webcache.googleusercontent.com/search? q=cache:bxTioIvhyvEJ:https://www.brennancenter.org/newsletter/justice-update-majority-statescut-both-crime-and-incarceration $+\& \mathrm{~cd}=1 \& \mathrm{hl}=\mathrm{en} \& \mathrm{ct}=\mathrm{clnk} \& \mathrm{gl}=\mathrm{us}]$

Bushway SD. The problem of prisoner (re)entry. Contemporary Sociology. 2006; 35(6):562-565. DOI: $10.1177 / 009430610603500607$

Chandler RK, Fletcher BW, Volkow ND. Treating drug abuse and addiction in the criminal justice system: improving public health and safety. Jama. 2009; 301(2):183-190. [PubMed: 19141766]

Deaner J, Jason LA, Aase D, Mueller D. The relationship betIen neighborhood criminal behavior and recovery homes. Therapeutic Communities. 2009; 30:89-93. [PubMed: 23487588]

De Leon G. Legal pressure in therapeutic communities. Journal of Drug Issues. 1988; 18(4):625-640.

De Leon, G. The Therapeutic Community: Theory, model, and method. New York: Springer Publishing Company; 2000.

De Leon G. Is the therapeutic community an evidence-based treatment? What the evidence says. Therapeutic Communities. 2010; 31(2):104-128.

Eaglin, J. California Quietly Continues to Reduce Mass Incarceration. Brennan Center for Justice: Justice for All. 2015 Feb 17. Accessed: 2015-12-14. Archived by WebCite ${ }^{\circledR}$ at http:// www.Webcitation.org/6dmHBsz2O

Harding DJ, Morenoff JD, Herbert CW. Home is hard to find neighborhoods, institutions, and the residential trajectories of returning prisoners. The ANNALS of the American Academy of Political and Social Science. 2013; 647(1):214-236. [PubMed: 23645931]

Heslin KC, Singzon T, Aimiuwu O, Sheridan D, Hamilton A. From personal tragedy to personal challenge: responses to stigma among sober living home residents and operators. Sociology of health \& illness. 2012; 34(3):379-395. [PubMed: 21707663]

Horwitz, S. How Jeff Sessions wants to bring back the war on drugs. The Washington Post. 2017 Apr 8. washingtonpost.com/world/national-security/how-jeff-sessions-wants-to-bring-back-the-waron534183a

Jason LA, Davis MI, Ferrari JR. The need for substance abuse after-care: longitudinal analysis of Oxford House. Addictive Behaviors. 2007; 32(4):803-818. [PubMed: 16843612] 
Jason LA, Groh DR, Durocher M, Alvarez J, Aase DM, Ferrari JR. Counteracting "Not in My Backyard": the positive effects of greater occupancy within mutual-help recovery homes. Journal of Community Psychology. 2008; 36(7):947-958. [PubMed: 22053121]

Jason, LA., Olson, BD., Foli, KJ. Rescued Lives: The Oxford House approach to substance abuse. New York: Routledge; 2008.

Jason LA, Olson BD, Harvey R. Evaluating alternative aftercare models for ex-offenders. Journal of Drug Issues. 2015; 45(1):53-68. [PubMed: 25641984]

Jason LA, Salina D, Ram D. Oxford recovery housing: Length of stay correlated with improved outcomes for women previously involved with the criminal justice system. Substance abuse. 2016; 37(1):248-254. [PubMed: 25962090]

King, R., Peterson, B., Elderbroom, B., Taxy, SA. How to reduce the federal prison population. Washington, DC: Urban Institute; 2015. Accessed: 2016-09-23. http:// Webcache.googleusercontent.com/search?q=cache:3WcveW0uZX4J:webapp.urban.org/reducingfederal-mass-incarceration/+\&cd=1\&hl=en\&ct=clnk\&gl=us

Lofstrom, M., Martin, B. Public Safety Realignment: Impacts so far. San Francisco, CA: 2015. Accessed: 2016-09-23. http://Webcache.googleusercontent.com/search? q=cache:z7QfmcXFby4J:www.ppic.org/main/ publication.asp0.000000i01164+\&cd=1\&hl=en\&ct=clnk\&gl=us

Martin SS, Butzin CA, Inciardi JA. Assessment of a multistage therapeutic community for druginvolved offenders. Journal of Psychoactive Drugs. 1995; 27(1):109-116. [PubMed: 7602434]

Mericle AA, Miles J, Cacciola J. A critical component of the substance abuse continuum of care: recovery homes in Philadelphia. Journal of Psychoactive Drugs. 2015; 47(1):80-90. [PubMed: 25715076]

National Association of Recovery Residences. A primer on recovery residences: FAQ. Atlanta, GA: 2012. p. 46Accessed: 2012-10-02. Archived by WebCite® at http://www.Webcitation.org/ $6 \mathrm{~B} 7 \mathrm{e} 01 \mathrm{VSk}$

Petersilia, J. When Prisoners Come Home: Parole and prisoner reentery. New York, NY: Oxford University Press; 2003.

Petteruti, A., Walsh, N. Jailing Communities: The impact of jail expansion and effective public safety strategies. Washington, DC: Justice Policy Institute; 2008. p. 33Accessed: 2012-03-23. [Archived by WebbCite® at http://www.Webcitation.org/66NoAJ4MD

Polcin DL. What about Sober Living Houses for parolees? Criminal Justice Studies. 2006; 19(3):291300.

Polcin DL. Co-occurring substance abuse and mental health problems among homeless persons: Suggestions for research and practice. Journal of social distress and the homeless. 2016; 25(1):110. [PubMed: 27092027]

Polcin DL, Henderson D, Trocki K, Evans K, Wittman F. Community context of Sober Living Houses. Addiction Research and Theory. 2012; 20(6):480-491. [PubMed: 24478615]

Polcin DL, Henderson DM, Korcha R, Evans K, Wittman FD, Trocki K. Perceptions of Sober Living Houses among addiction counselors and mental health therapists: knowledge, views and perceived barriers. Journal of Psychoactive Drugs. 2012; 44(3):224-236. [PubMed: 23061322]

Polcin DL, Korcha R, Bond J, Galloway GP. Sober living houses for alcohol and drug dependence: 18month outcomes. Journal of Substance Abuse Treatment. 2010; 38(4):356-365. [PubMed: 20299175]

Polcin, DL., Korcha, RA., Wittman, FD., Troutman, D. Sober Living Houses for Offenders: Outcomes and barriers. Presented at the California Department of Alcohol and Drug Programs Conference; Sacramento, CA. October 13; 2010.

Polcin DL, Mericle A, Callahan S, Harvey R, Jason LA. Challenges and rewards of conducting research on recovery residences for alcohol and drug disorders. Journal of Drug Issues. 2016; 46(1):51-63. DOI: 10.1177/0022042615616432 [PubMed: 26834279]

Polcin DL, Mericle A, HoIll J, Sheridan D, Christensen J. Maximizing social model principles in residential recovery settings. Journal of Psychoactive Drugs. 2014; 46(5):436-443. DOI: 10.1080/02791072.2014.960112 [PubMed: 25364996] 
Porter, ND. State advances in criminal justice reform. Vol. 2016. Washington, DC: The Sentencing Project; 2017. Accessed: 2017-02-02. Archived by WebCite® at http://www.Webcitation.org/ 6nzHrLSwM

Prendergast ML, Hall EA, Ixler HK, Melnick G, Cao Y. Amity prison-based therapeutic community: 5-year outcomes. The Prison Journal. 2004; 84(1):36-60.

Roeder O, Eisen L, Bowling J. What caused the crime decline?. 2015 Accessed 2017-09-14.

Brennan Center for Justice; New York: https://www.brennancenter.org/publication/what-caused-crimedecline

Sentencing Project. Criminal Justice Facts. Washington, DC: The Sentencing Project; 2016. Accessed: 2017-02-02. Archived by Website ${ }^{\circledR}$ at http://www.sentencingproject.org/criminal-justice-facts/

Tsemberis S, Gulcur L, Nakae M. Housing First, consumer choice, and harm reduction for homeless individuals with a dual diagnosis. American Journal of Public Health. 2004; 94:651-656. [PubMed: 15054020]

Wagner, P., Rabuy, B. Mass incarceration: the whole pie. Vol. 2016. Northampton, MA: Prison Policy Initiative; 2016. Accessed: 2017-02-02. Archived by WebCite ${ }^{\circledR}$ at http://www.webcitation.org/ 6nzIJfqnU

Warren, J. State ordered to ease prison overcrowding: Federal judge threatens to impose a population cap if conditions don't improve markedly within six months. Los Angeles Times; 2006 Dec 12. http://www.latimes.com/news

Waul, M., Travis, J., Solomon, AL. Background paper: the effect of incarceration and reentry on children, families, and communities (From Prisons to Home Conference). Washington, DC: Urban Institute; 2002. Accessed: 2017-02-02. Archived by WebCite ${ }^{\circledR}$ at http://www.webcitation.org/ 6nzHBqqG2 